\title{
Montelukast improves regional air-trapping due to small airways obstruction in asthma
}

\author{
M.R. Zeidler*, E.C. Kleerup*, J.G. Goldin\#, H.J. Kim", D.A. Truong ${ }^{\#}$, M.D. Simmons*, \\ J.W. Sayre\#, W. Liu", R. Elashoff" and D.P. Tashkin*
}

ABSTRACT: Quantitative image analysis of high-resolution computed tomography (HRCT) performed at residual volume, before and after methacholine, is a sensitive method of detecting small airways involvement in asthma and response to therapy targeted to the small airways. Since an oral anti-leukotriene reaches the small airways via the circulation, the present authors hypothesised that treatment with montelukast would lead to improved small airway patency.

A double-blind crossover study compared the effect of montelukast versus placebo for 4 weeks in $\mathbf{1 6}$ mild-to-moderate steroid-naïve asthmatics. Small airways function was evaluated by HRCT at residual volume before and after methacholine to assess regional air-trapping and airways hyperresponsiveness, as well as by physiological studies of small airways.

Montelukast treatment resulted in significantly less regional air-trapping on HRCT on the premethacholine images when compared with placebo, as well as improvement in total quality of life scores and symptom sub-scores. However, montelukast treatment had no effect on increases in regional air-trapping on HRCT in response to methacholine. No differences were noted in global measures of small airways physiology between placebo and montelukast.

In conclusion, distal airways disease improves in asthmatic subjects treated with montelukast. This improvement can be detected with high-resolution computed tomography, but not with conventional physiological studies.

KEYWORDS: Methacholine, montelukast, quantitative thoracic computed tomography of asthma, small airways

mall airways disease (airways $<2 \mathrm{~mm}$ in diameter), long recognised as a component of asthma, has been relatively unexplored due to difficulties in evaluating and treating the peripheral airways. Increased mucous plugging and thickening of the smooth muscle, submucosa and adventitia have been demonstrated in the peripheral airways of patients who died from asthma [1-3]. Activated eosinophils and expression of interleukin-5 mRNA are also increased in the distal resected lung of patients with moderate-to-mild asthma $[4,5]$. Using transbronchial and endobronchial biopsies, more eosinophilic inflammation was documented in the distal lung than in the central airways of nocturnal asthmatics [6]. Histopathological data, obtained from autopsies, lung resections and bronchoscopical studies, offer invaluable insight into small airways disease in asthma, but are difficult to obtain and/or expose the patient to potential risks.

Noninvasive small airways physiological studies are easier to perform, but are limited by their

For Editorial comments see page 250 . test-retest variability and/or lack of specificity in reflecting small airways function. Forced expiratory flow rates at mid-to-low lung volumes exhibit marked variability and may be affected by changes in the large airways and lung volumes [7]. Closing volume (CV), believed to be a more specific test for assessing distal lung disease, is limited by large, within-subject and inter-reader variability [8]. However, a recent study positively correlated $\mathrm{CV}$ with repeated asthma exacerbations [9].

Quantitative image analysis of high-resolution computed tomography (HRCT) performed at residual volume (RV), before and after bronchoprovocation, identifies regional small airways changes not detectable by physiological measures [10-12]. In a comparison of an extra-fine inhaled corticosteroid (ICS), beclomethasone dipropionate (BDP) hydrofluoroalkane (HFA; mass median aerodynamic particle size (MMAD) $0.8-1.2 \mu$ ), with a conventional large particle chlorofluorocarbon (CFC) ICS, BDP-CFC (MMAD 3.5-4.0 $\mu$ ), regional air-trapping decreased after treatment with BDP-HFA, but not with BDP-CFC [13]. In
AFFILIATIONS

*Division of Pulmonary, Critical Care Medicine and Hospitalists,

\#Thoracic Radiology Section, Dept of Radiology, and

'Division of Biomathematics, Dept of Medicine, David Geffen School of Medicine at the University of California, Los Angeles, CA, USA.

CORRESPONDENCE

M.R. Zeidler

David Geffen School of Medicine at the University of California Los Angeles Division of Pulmonary Critical Care Medicine and Hospitalists

CHS 37-131 10833 Le Conte Ave. Los Angeles CA 90095-1690 USA

Fax: 13102065088 E-mail: mzeidler@mednet.ucla.edu

Received:

January 132005

Accepted after revision:

October 242005

\section{SUPPORT STATEMENT}

Merck \& Co. Inc. (North Wales, PA, USA) supplied the montelukast and matching placebo in addition to partly funding this study with an unrestricted medical school grant. 
contrast, neither of these two treatments led to a significant difference in the luminal size of measured large $(>2 \mathrm{~mm})$ airways on HRCT. In addition, no significant difference in RV, functional residual capacity (FRC) or forced mid-expiratory flow at $25-75 \%$ of vital capacity (FEF25-75\%) was found between the two groups.

The present authors hypothesised that improvement in HRCT lung attenuation and CV would occur in asthmatic subjects treated with montelukast, a systemically administered leukotriene receptor antagonist with anti-inflammatory properties, which would target both proximal and distal airways.

\section{MATERIALS AND METHODS Study design}

The study compared oral montelukast and placebo in a randomised, double-blind, placebo-controlled crossover trial. The primary outcome was the change in regional air-trapping assessed by HRCT at RV, before and after methacholine. Secondary outcomes included changes in $\mathrm{CV}$, spirometric indices, peak expiratory flow rate (PEFR), subdivisions of lung volume, rescue $\beta$-agonist use, asthma symptom and asthma control scores, and quality of life.

After baseline measurements, subjects were randomised to either montelukast $10 \mathrm{mg}$ or an identical-appearing placebo to be taken once daily in the evening. After 4 weeks, subjects crossed over to the alternate treatment. A compliance visit was performed 2 weeks after the initiation of each drug phase (table 1).

\section{Subjects}

Inclusion criteria were: 1) aged 18-65 yrs; 2) no use of ICS in the prior 2 months; 3 ) forced expiratory volume in one second (FEV1) $\geqslant 60 \%$ predicted [14]; 4) provocative dose causing a $20 \%$ fall in FEV1 (PC20) $\leqslant 4 \mathrm{mg} \cdot \mathrm{mL}^{-1}$; and 5 ) clinical diagnosis of asthma. Exclusion criteria are listed in table 2. Females of childbearing age were instructed to use appropriate birth control measures.

Subjects were informed of the risks and benefits of the study and signed an informed consent approved by the University of California Medical Human Subjects Protection and Radiation Safety Committees (Los Angeles, CA, USA).

\section{TABLE 2 Exclusion criteria for entry into the study}

\begin{tabular}{|c|c|}
\hline Exclusion criteria & Time frame for exclusion \\
\hline Inhaled corticosteroids & Used within 2 months \\
\hline Parenteral or oral steroids & Used within 6 months \\
\hline $\begin{array}{l}\text { Anti-leukotrienes, cromolyn sodium } \\
\text { or nedocromil }\end{array}$ & Used within 2 months \\
\hline $\begin{array}{l}\text { Theophylline or } \beta \text {-adrenergic blocking } \\
\text { agents }\end{array}$ & Used within 1 month \\
\hline Tobacco & $\begin{array}{l}\text { Used within the past year or cumulative } \\
\text { smoking history }>5 \text { pack-yrs }\end{array}$ \\
\hline $\begin{array}{l}\text { Respiratory infection or an influenza } \\
\text { vaccination }\end{array}$ & Within 3 weeks \\
\hline Clinically significant medical problems & Investigator discretion \\
\hline $\begin{array}{l}\text { Participation in study using an } \\
\text { experimental medication }\end{array}$ & Within 1 month \\
\hline Pregnant or lactating females & \\
\hline
\end{tabular}

\section{Procedures}

Pulmonary function and methacholine inhalation challenge testing

Subjects withheld albuterol $8 \mathrm{~h}$ prior to all procedures. Pulmonary function tests, methacholine challenge tests and $\mathrm{CV}$ were performed as per published guidelines. Identification of $\mathrm{CV}$ was performed visually by two independent readers on separate printouts of the single-breath nitrogen washout curves and averaged.

\section{Functional imaging}

The HRCT acquisition technique has been described previously $[11,13]$.

\section{HRCT data analysis}

Anatomically registered 1-mm slices, which were obtained pre- and post-methacholine at baseline (visit three) and after 4 weeks of treatment with either drug (visits six and nine), were selected for the rostral (upper) and caudal (lower) lung zones. Following image quality checks, automated segmentation was performed on each of the acquired slices as previously described [11]. Twelve nonoverlapping regions of interest

\section{TABLE 1 Study design}

\begin{tabular}{|c|c|c|c|c|c|c|c|c|c|}
\hline \multirow{2}{*}{$\begin{array}{l}\text { Tests } \\
\text { Visit }\end{array}$} & \multirow{2}{*}{$\begin{array}{c}\text { Screening } \\
1\end{array}$} & \multicolumn{2}{|c|}{ Baseline } & \multicolumn{3}{|c|}{ Drug phase I } & \multicolumn{3}{|c|}{ Drug phase II } \\
\hline & & 2 & 3 & 4 & 5 & 6 & 7 & 8 & 9 \\
\hline Day $^{\#}$ & 0 & 14 & 15 & 29 & 43 & 44 & 58 & 72 & 73 \\
\hline Spirometry & $\cdot$ & - & & - & ๑ & & $\cdot$ & $\cdot$ & \\
\hline Methacholine challenge test & $\bullet$ & & & & & & & & \\
\hline Plethysmography/closing volume & & $\bullet$ & & & ฯ & & & $\bullet$ & \\
\hline HRCT with methacholine challenge & & & 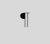 & & & $\uparrow$ & & & $\bullet$ \\
\hline Questionnaires & $\bullet$ & & $\bullet$ & & & $\bullet$ & & & ・ \\
\hline Diary/peak expiratory flow recording & $\cdot$ & & 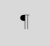 & - & & ・ & $\bullet$ & & ・ \\
\hline
\end{tabular}

HRCT: high-resolution computed tomography. ${ }^{*}$ : assuming a 14 -day run-in; $\urcorner$ : tests performed. 
(ROIs) were segmented from the lung portion of the matched slices. The 12 ROIs consisted of right rostral, right caudal, left rostral and left caudal regions, each subdivided into ventral (nondependent), intermediate and dorsal (dependent) sections. The latter three subdivisions mimic the gravity-dependent zones of lung perfusion in supine subjects by WEST [15]. A higher attenuation is expected in the dependent regions due to a relative increase in blood per unit tissue volume. Lung attenuation curves (LACs) representing the cumulative frequency distribution of lung attenuation (Hounsfield units; HU) by pixel were derived for each of the ROIs and the median and 10th percentile attenuation were determined (fig. 1). A shift of the LAC to the left (as measured by a more negative median or 10th percentile) represents lower lung attenuation, more airtrapping, and by inference, reduced small airways patency [11]. Shifts in lung attenuation after administration of methacholine at baseline and after each treatment arm were also evaluated.
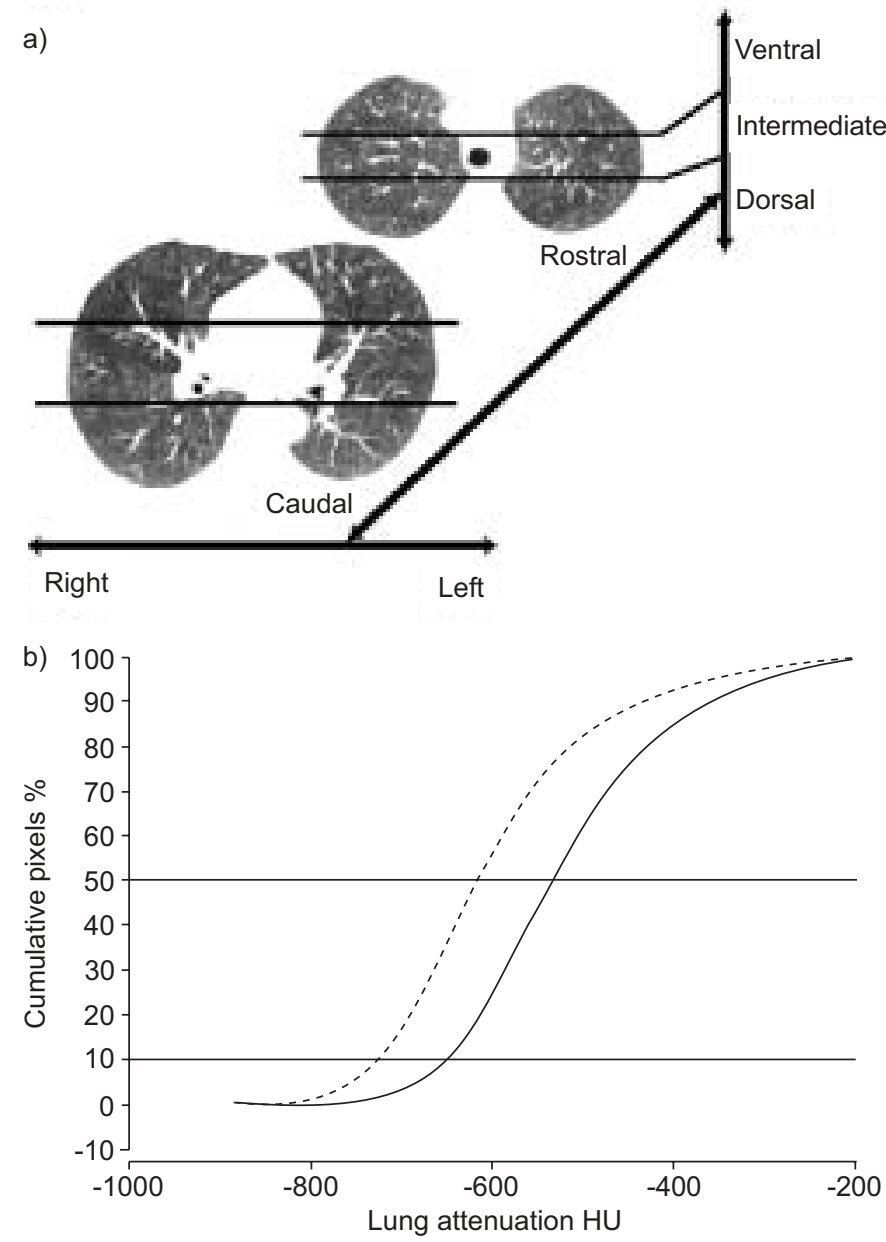

FIGURE 1. a) High-resolution computed tomography data analysis showing the acquisition of 12 regions of interest (ROIs), consisting of right rostral, right caudal, left rostral and left caudal regions, each subdivided into ventral (nondependent), intermediate and dorsal (dependent) sections. A lung attenuation curve (LAC) is then derived for each ROI. b) LAC representing the cumulative frequency distribution of lung attenuation by pixel. HU: Hounsfield units. - : before methachloine; - - -: after methacholine.
Data analysis

The General Linear Model procedure was used to test for a sequence group effect. According to the planned analysis, if no sequence group effect was noted ( $F$ with a corresponding $p \geqslant 0.05$ ), a mixed model would be used, including a sequence effect, representing the two randomised groups, a period effect, with two levels, and a treatment effect with two levels. Subjects were tested within a sequence group and adjustments were made for baseline values. Alternatively, if a sequence effect was detected $(p<0.05)$, then the data from the first treatment period would be analysed using a two-sample unpaired t-test and the data from the second period would be discarded. Ordinal data from questionnaires and diaries were evaluated using a nonparametric signed rank test. Since the $\mathrm{CV}$ as a per cent of the vital capacity $(\mathrm{CV} / \mathrm{VC})$ values and per cent predicted distributions were skewed, a Kruskal-Wallis test was used.

Changes in the 10th percentile and median lung attenuations after, compared with before, treatment (i.e. post-treatment with placebo minus baseline or with montelukast minus baseline) were calculated from both the pre-methacholine and postmethacholine LACs, separately, as well as from the difference between the pre- and post-methacholine curves (i.e. the shift in the curves in response to methacholine).

\section{RESULTS}

A total of 27 subjects were enrolled in the trial. Seven of these withdrew during the run-in period, of whom three were noncompliant with appointments, two had scheduling conflicts due to change in work schedule and jury duty, one had a significant psychiatric history undisclosed at screening and one had claustrophobia and could not complete the baseline computed tomography scan. The 20 remaining subjects were randomised, four of whom withdrew early for the following reasons: two had asthma exacerbations during the study which required prednisone; one was noncompliant with appointments; and one had an increase in migraine headaches (during the first drug phase while on placebo). The remaining 16 subjects completed all nine study visits.

Baseline demographics of the 16 completed subjects are presented in table 3 .

\section{Quantitative image analysis of HRCT}

A significant sequence effect was noted in the HRCT analysis. Therefore, the HRCTs were analysed as parallel groups, with eight subjects randomised to montelukast and eight subjects randomised to placebo. Two scans could not be evaluated due to motion artefacts resulting in seven scans per treatment group and 168 evaluable ROIs. Baseline HRCT findings (table 4) indicate significantly more air-trapping (lower median and 10th percentile lung attenuation before methacholine) in the montelukast group compared with the placebo group $(\mathrm{p}=0.0001)$.

Small but consistent and statistically significant increases in regional lung attenuation (pre-methacholine) were noted after treatment in individuals randomised to montelukast compared with baseline ( $\mathrm{p}<0.0001$; table 4 ; figs 2 and 3$)$. These findings imply reduced air-trapping after 4 weeks of treatment with montelukast, probably due to improved small airways 


\begin{tabular}{lc} 
TABLE 3 & Baseline demographics \\
\hline Age yrs & $36.0 \pm 13.5(19.8-65.8)$ \\
Female \% & 43.8 \\
Race/ethnicity & \\
$\quad$ African-American \% & 18.8 \\
$\quad$ Hispanic \% & 12.5 \\
Asthma symptoms & \\
$\quad$ Duration yrs & $22.5 \pm 12.1(6.6-53.9)$ \\
$\quad$ Age of onset yrs & $14.6 \pm 15.1(2.0,55.0)$ \\
\hline
\end{tabular}

Data are presented as mean $\pm S D$ (range) or $\% .{ }^{*}: n=16$.

patency. In contrast, the placebo group showed a decrease in regional lung attenuation (pre-methacholine) after treatment, indicating an increase in air-trapping $(\mathrm{p}<0.0002)$. The difference between montelukast and placebo was statistically significant $(\mathrm{p}<0.0001)$.

Prior to treatment, administration of methacholine resulted in significant regional air-trapping on HRCT at RV in both treatment groups (table 4). One (10th percentile per cent change) of four measures of methacholine response was greater in the placebo than the montelukast group at baseline $(p=0.0379)$. Treatment with montelukast did not lead to any reduction in the degree of air-trapping after methacholine $(\mathrm{p}>0.25)$. In contrast, treatment with placebo resulted in a slight but significant decrease in airway responsiveness to methacholine $(p<0.026)$. This finding was associated with a significant difference (in three out of four measures of methacholine response) between the placebo and montelukast treatment groups $(\mathrm{p}<0.04)$. No difference was seen in the change in FEV1, PC20 or the fall in FEV1 after a fixed methacholine dose following treatment with either montelukast or placebo, nor were the differences between the two groups significant (table 5).

Comparing the baseline and post-treatment scans before methacholine in the placebo group, the anatomically paired ROIs correlated better with one another (intraclass correlation (ICC) $0.87 ; 95 \%$ CI $0.83-0.90 ; p=0.02$ ) than the contralaterally paired ROIs (ICC 0.83 ; 95\% CI 0.77-0.88) and far better than randomly paired ROIs (ICC $0.55 ; 95 \%$ CI $0.34-0.76$ ). These findings are consistent with a heterogeneous distribution of air-trapping within the lung.

\section{Physiological studies}

Results of the physiological studies, including baseline values, are shown in table 5 . No sequence effect was noted for the

TABLE 4 Lung attenuation values at baseline and change from baseline after 4 weeks of either montelukast or placebo

\begin{tabular}{|c|c|c|c|c|c|}
\hline & \multicolumn{2}{|c|}{ Placebo $^{\#}$} & \multicolumn{2}{|c|}{ Montelukast $^{\#}$} & \multirow{2}{*}{$\begin{array}{c}\text { Placebo versus } \\
\text { montelukast } p \text {-value }\end{array}$} \\
\hline & Mean \pm SD & p-value & Mean \pm SD & p-value & \\
\hline \multicolumn{6}{|l|}{ Baseline: median } \\
\hline Before methacholine HU & $-589 \pm 91$ & & $-651 \pm 109$ & & 0.0001 \\
\hline Shift with methacholine $\mathrm{HU}^{+}$ & $-91 \pm 66$ & & $-79 \pm 71$ & & 0.2834 \\
\hline Before methacholine HU & $-693 \pm 80$ & & $-745 \pm 92$ & & 0.0001 \\
\hline Shift with methacholine $\mathrm{HU}^{+}$ & $-75 \pm 57$ & & $-61 \pm 52$ & & 0.0941 \\
\hline Shift with methacholine \% & $-11.5 \pm 9.8$ & & $-8.6 \pm 8.0$ & & 0.0379 \\
\hline \multicolumn{6}{|l|}{$\begin{array}{l}\text { Change from baseline after } \\
\text { treatment: median }\end{array}$} \\
\hline Before methacholine $\mathrm{HU}^{\S}$ & $-22 \pm 52$ & $p=0.0002^{f}$ & $39 \pm 48$ & $\mathrm{p}<0.0001^{f}$ & $<0.0001$ \\
\hline Before methacholine $\mathrm{HU}^{\S}$ & $-19 \pm 45$ & $p=0.0002$ & $33 \pm 40$ & $p<0.0001$ & $<0.0001$ \\
\hline Before methacholine \% & $-3.1 \pm 6.8$ & $p=0.0001$ & $4.4 \pm 5.4$ & $p<0.0001$ & $<0.0001$ \\
\hline Shift with methacholine $\mathrm{HU}^{\# \#}$ & $17 \pm 48$ & $p=0.0017$ & $-3 \pm 4$ & $p=0.5357$ & 0.0073 \\
\hline Shift with methacholine \% & $2.9 \pm 8.0$ & $p=0.0012$ & $-1.0 \pm 7.9$ & $p=0.2529$ & 0.0017 \\
\hline
\end{tabular}

$\mathrm{HU}=$ Hounsfield units. ${ }^{*}$ : high-resolution computerised tomography (HRCT) data were analysed for subjects randomised to the first treatment phase only (equivalent to a parallel-group design) due to a sequence effect in the cross-over study. The HRCT scan from one the eight subjects in each treatment group could not be analysed due to motion artefacts yielding $n=7$ for each group. ${ }^{\bullet}: p$-value two-sample unpaired t-test between treatments. ${ }^{+}$: negative absolute or per cent shift after methacholine represents lower lung attenuation indicating more air-trapping. ${ }^{\varsigma}$ : positive absolute or per cent change from baseline represents higher lung attenuation indicating less air-

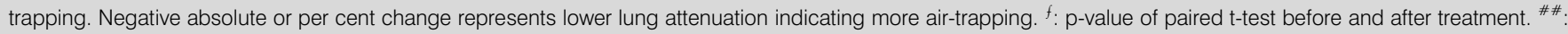
negative absolute or per cent change in shift after methacholine represents more hyperresponsiveness to methacholine. Positive absolute or per cent change in shift after methacholine represents less hyperresponsiveness. 

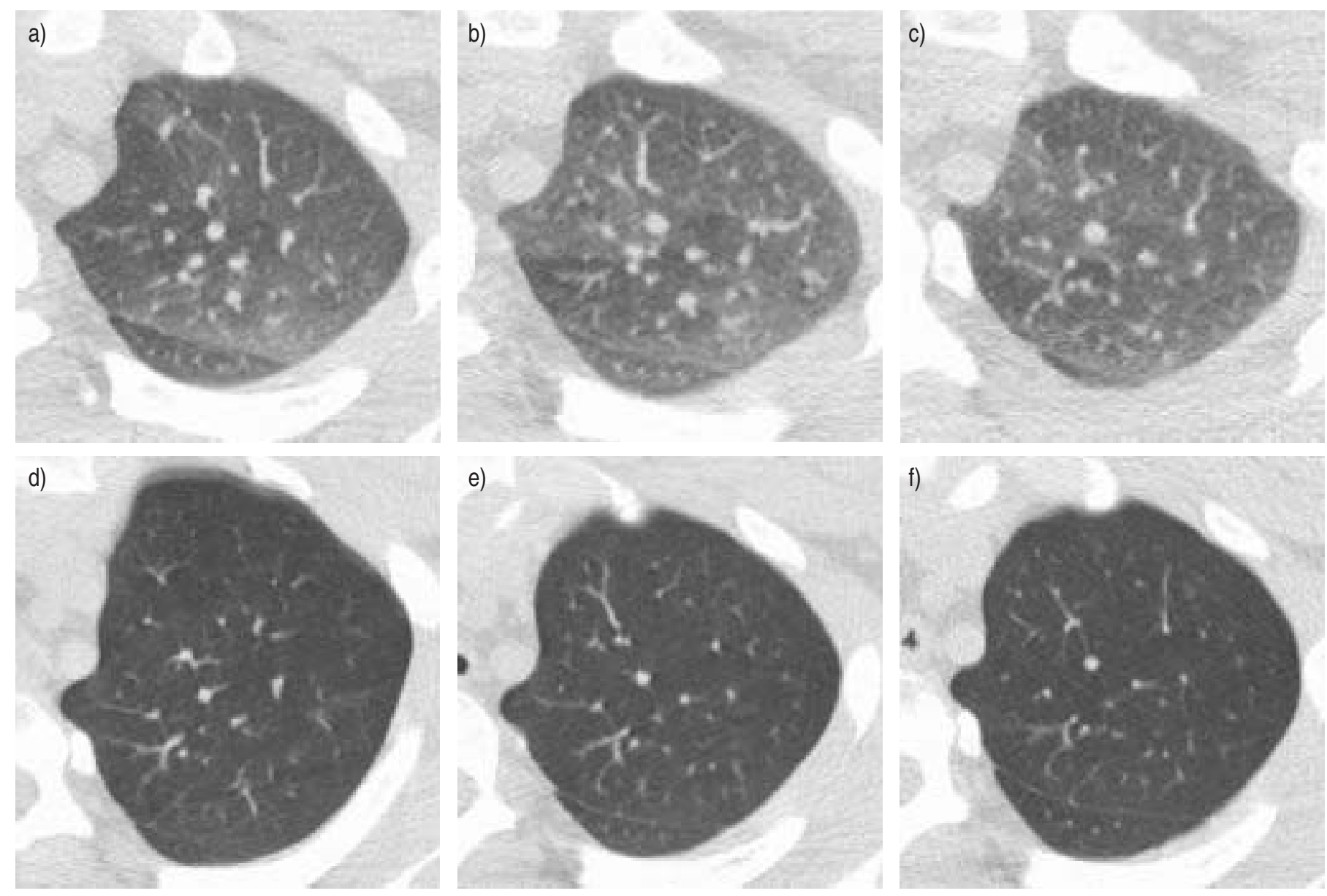

FIGURE 2. High-resolution computed tomography (HRCT) images of an individual subject all obtained before a methacholine challenge at: a) baseline; b) after 4 weeks of treatment with montelukast; and c) after 4 weeks of placebo treatment. $d$, e, f) Matched HRCT images from the same subject at corresponding time points after a methacholine challenge.

results of these studies and the data were analysed using the mixed model. FEV1 showed improvement in the montelukast groups that approached statistical significance compared with placebo $(p=0.0525)$. However, none of the physiological measures of small airways disease (FEF25-75\%, RV, RV/total lung capacity, FRC or CV/VC) showed any significant change from baseline after treatment with either placebo or montelukast. Analysis of the impact of treatment on CV was markedly limited since only 77 out of 119 measures had a detectable inflection point. Of the 16 subjects, two had no inflection point in all three studies, one subject had no inflection point in two studies, and seven subjects had no inflection point in one study.

\section{Subject-reported outcomes}

Improvements in the Mini Asthma Quality of Life Questionnaire overall score and symptom sub-scores were statistically significant in favour of montelukast [18]. Changes in several other subject-reported outcome variables were numerically, but not statistically, more favourable with montelukast than placebo (table 6).

\section{Correlation of results}

A positive correlation was found between improvement in lung attenuation pre-methacholine (shift in the 10th percentile or median) and improvement in the overall mini quality of life score (median HU: $\mathrm{r}=0.771, \mathrm{p}<0.0013$; 10th percentile HU: $\mathrm{r}=0.763 ; \mathrm{p}<0.0015$ ) and the symptom sub-scores (median HU: $\mathrm{r}=0.539 ; \mathrm{p}<0.0466 ; 10$ th percentile HU: $\mathrm{r}=0.511 ; \mathrm{p}<0.0616$ ) after treatment with montelukast. No changes in any of the measures of small airways physiology correlated with changes in lung attenuation.

\section{DISCUSSION}

Findings from the present study suggest that treatment with a leukotriene receptor antagonist in mild-to-moderate asthmatic subjects has a beneficial effect on small airways patency. However, this effect could only be documented by changes in radiographical features consistent with improvement in small airways function (reduction in regional air-trapping), but not with changes in physiological measures of small airways disease. Conversely, the possibility that these findings might have been influenced by the significantly greater degree of regional air-trapping noted on HRCT at baseline in the montelukast compared with the placebo group cannot be excluded. However, these findings are consistent with previously reported results indicating persistence of $\mathrm{RV}>150 \%$ pred after inhaled salmeterol/fluticasone therapy correlating with the presence of qualitatively assessed low attenuation 


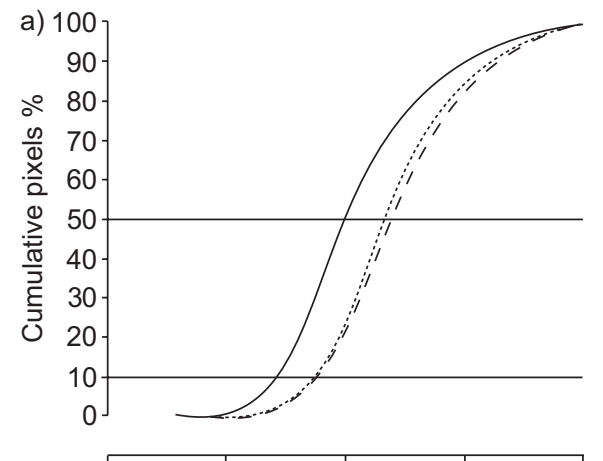

b)
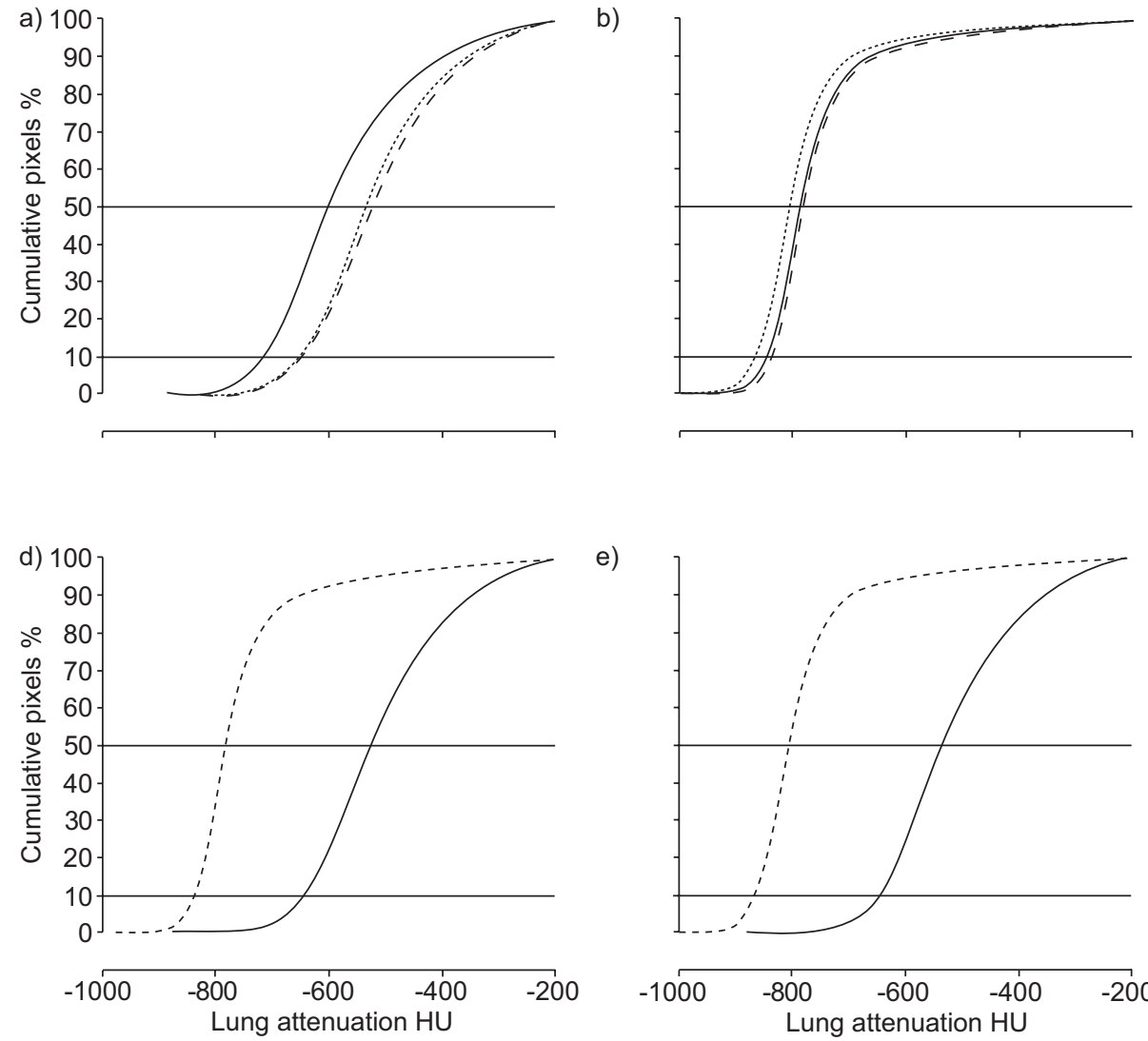

e)

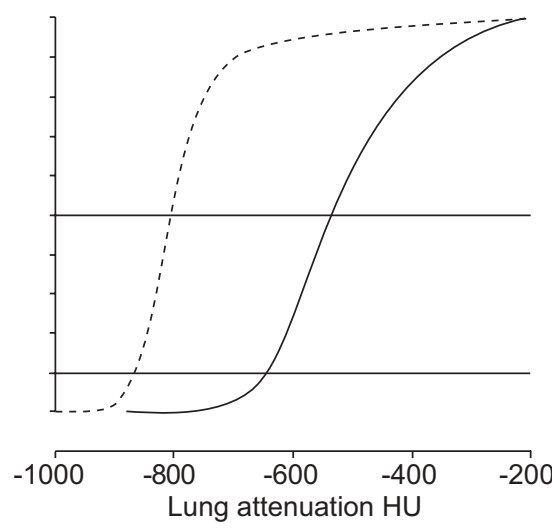

c)

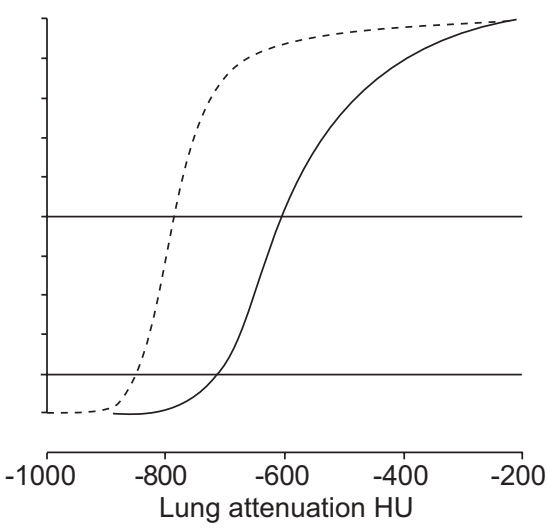

FIGURE 3. Quantitative image analysis. a) Lung attenuation curves (LACs) before methacholine challenge at baseline $(-)$ and after 4 weeks of montelukast (---) or placebo (…). After treatment, the shift in the LAC to the right from the baseline curve is apparent after montelukast, which carried over into the subsequent placebo phase of the trial. b) LACs after methacholine challenge at baseline $(-)$ and after 4 weeks of either montelukast (----) or placebo treatment (…). A small but similar shift from the baseline post-methacholine LAC is noted after montelukast and placebo, indicating persistent regional hyperresponsiveness to methacholine throughout each treatment phase. c, d, e) LACs before $(-)$ and after $(\cdots \cdot \cdot)$ methacholine which were derived at baseline and after 4 weeks of montelukast or placebo, respectively. HU: Hounsfield units. areas on HRCT even after normalisation of FEV1 and FEF25$75 \%$ [21].

The HRCT evidence of decreased air-trapping after treatment with montelukast noted in the present study parallels the previously reported HRCT findings of decreased regional airtrapping after an extra-fine ICS (HFA-BDP), which penetrates the distal lung, compared with a coarse ICS (CFC-BDP), which deposits mainly in the large airways [13]. No differences were noted in changes in large $\left(>2 \mathrm{~mm}^{-2}\right)$ airways diameters or FEV1 between the two treatments in the latter study. These observations support the concept that the improvement in airtrapping reflects an effect on small airways function and not an improvement in large airway function.

The beneficial effects observed in the current study with montelukast on regional air-trapping, may reflect the fact that cysteinyl leukotrienes (CysLT) are potent bronchoconstrictors and may differentially affect the small airways more than the larger airways. In nonasthmatic lung resection samples, CysLT produced a 30-fold greater bronchoconstriction in small airways (0.5-2 $\mathrm{mm}$ internal diameter) than in large airways (3-6 mm) [22]. In smaller bronchioles $(0.3-0.5 \mathrm{~mm}$ internal diameter), leukotriene D4 causes constriction primarily by activating $\mathrm{Ca}^{2+}$ entry via nonvoltage gated channels, possibly by a phosphatidylcholine phospholipase $C$ mediated pathway [23]. Montelukast is a potent antagonist of all three CysLT in both small and large excised airways via the CysLT $_{1}$ receptor subtype [22]. In excised small airways (1.5 $\mathrm{mm}$ external diameter), passively sensitised with serum from allergic individuals and challenged with grass-pollen extract, an early allergic contractile response was attenuated in only some cases by leukotriene or thromboxane receptor antagonists and almost completely in all individuals by the combination of both types of antagonists [24].

The present authors' failure to observe an improvement in physiological indices of small airways function following montelukast therapy probably reflects the poor sensitivity of these measures in detecting changes due to the large degree of intra-subject test variability $[25,26]$. The current authors chose to study $\mathrm{CV}$ because of previous reports suggesting it to be a sensitive, specific and reproducible physiological indicator of small airways disease [16]. In addition, in subjects with brittle asthma it may be a sensitive tool for predicting asthma exacerbations, suggesting that it might serve as a useful marker of chronic untreated distal airways inflammation in these patients [9]. However, in the mild asthmatic participants in the present study, while there was good inter-reader agreement of $\mathrm{CV}$ interpretation, the single-breath nitrogen washout curves of several subjects did not have a clear inflection point at various times in the study and some subjects were unable to produce acceptable and reproducible curves, even after multiple attempts.

The authors believe that global physiological tests may be an insensitive marker of changes in small airways pathology in asthma due, at least in part, to the heterogeneous regional involvement of small airways that may be detected more 
TABLE 5 Spirometry, methacholine challenge and lung volume values at baseline and change from baseline after 4 weeks of either montelukast or placebo ${ }^{\#}$

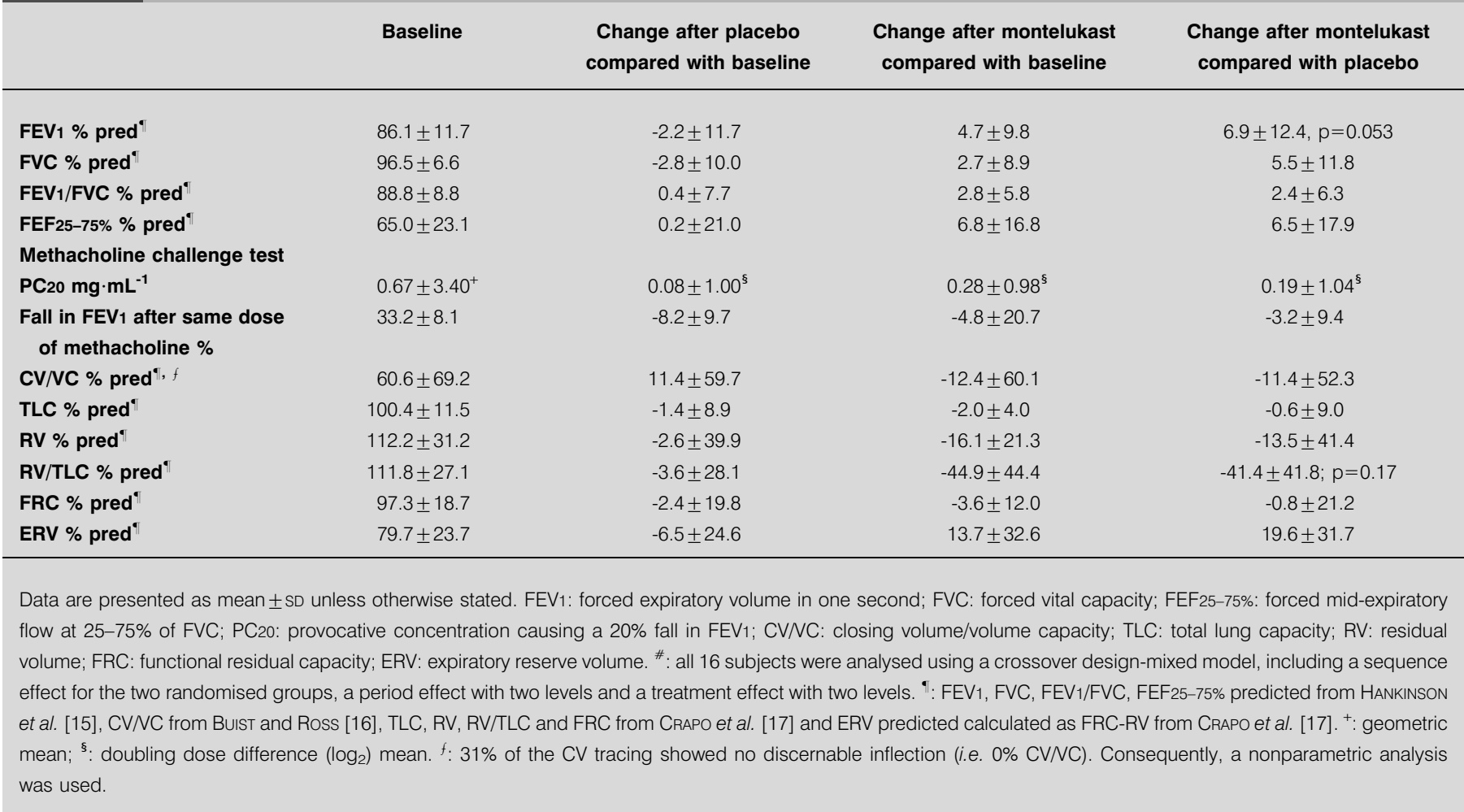

TABLE 6 Subject-reported outcomes at baseline and change from baseline after 4 weeks of either montelukast or placebo ${ }^{\#}$

\begin{tabular}{|c|c|c|c|c|}
\hline & Baseline & $\begin{array}{l}\text { Change after placebo } \\
\text { compared with baseline }\end{array}$ & $\begin{array}{l}\text { Change after montelukast } \\
\text { compared with baseline }\end{array}$ & $\begin{array}{l}\text { Change after montelukast } \\
\text { compared with placebo }\end{array}$ \\
\hline \multicolumn{5}{|l|}{ Mini asthma quality of life [18] } \\
\hline Overall score & $4.7 \pm 1.4$ & $0.1 \pm 0.3$ & $0.5 \pm 0.8$ & $0.4 \pm 0.7 ; p=0.045$ \\
\hline Symptoms sub-score & $4.7 \pm 1.4$ & $0.0 \pm 0.5$ & $0.5 \pm 0.7$ & $0.5 \pm 0.7 ; p=0.022$ \\
\hline Asthma symptoms utility index [19] & $0.74 \pm 0.21$ & $0.03 \pm 0.15$ & $0.06 \pm 0.17$ & $0.03 \pm 0.18$ \\
\hline am \% pred [14] & $94.4 \pm 14.2$ & $1.6 \pm 6.6$ & $7.6 \pm 12.7$ & $2.3 \pm 9.7$ \\
\hline pm \% pred & $88.8 \pm 15.4$ & $3.7 \pm 4.3$ & $7.4 \pm 5.0$ & $1.8 \pm 2.2$ \\
\hline $\begin{array}{l}\text { Rescue albuterol } 1 \text { week mean } \\
\text { puffs } 24 \mathrm{~h}^{-14}\end{array}$ & $2.7 \pm 2.5$ & $0.1 \pm 1.7$ & $-1.0 \pm 1.2$ & $-1.0 \pm 2.1$ \\
\hline Nocturnal awakenings $\cdot$ week $^{-1}$ & $0.4 \pm 0.6$ & $0.0 \pm 0.5$ & $-0.1 \pm 0.4$ & $-0.3 \pm 0.6$ \\
\hline
\end{tabular}

readily by radiographical imaging techniques. Quantitative analysis of individual HRCTs, before and after methacholine challenge, clearly showed that not all analysed lung segments in any given subject had small airways abnormalities. This inhomogeneous pattern of small airways involvement may explain why global studies of airway physiology may not adequately reflect the magnitude of changes in the small airways.

The heterogeneity as well as the subtlety of small airways airtrapping may also explain why qualitative radiographical techniques may not be adequate to assess distal lung disease. 
Initial qualitative radiographic techniques, utilised for the evaluation of air-trapping in obstructive pulmonary disease, were confounded by marked intra- and inter-reader variability (e.g. Kappa Statistic: 0.60-0.79 and 0.40-0.64, respectively), yielding conflicting results [27]. Computer-derived quantitative image analysis of HRCT is necessary for reliable detection and quantitation of air-trapping due to small airways disease differences that may be indistinguishable to the eye.

The lack of clearly significant spirometric improvement in response to montelukast, in comparison with placebo, in the current study is not surprising in light of the mild severity of asthma and the small number of subjects studied. The $6.9 \pm 12.4 \%$ pred FEV1 response noted after montelukast compared with placebo is comparable to findings from other studies, which showed improvements of $\sim 7 \%$ pred from baseline [28-30]. The 6.5\% pred improvement in FEF25-75\% did not reach statistical significance, but agrees well with an $8 \%$ pred response seen in a prior study [28].

In the present study, the use of montelukast did not reduce hyperresponsiveness to methacholine either globally as assessed by decline in FEV1 or regionally as indicated by the lack of any impact on the leftward shift (in the direction of lower attenuation) of the LAC. This finding contrasts with a small but statistically significant improvement in regional methacholine responsiveness in the placebo group. The latter might be attributable to the deterioration in pre-methacholine lung attenuation following placebo treatment, a "floor effect" (i.e. subjects may have reached near maximal air-trapping prior to methacholine administration, leaving little room for further air-trapping in response to bronchoprovocation).

The lack of improvement in airway reactivity measured by FEV1 after treatment with montelukast is consistent with most but not all of the published literature. An increase of only 0.45 doubling concentrations was seen with montelukast compared with 0.14 for placebo $(p=0.16)$ [31], and an increase of 1.5 (95\% CI: 1.0-2.3) doubling doses was seen with montelukast compared with 1.7 (95\% CI: 1.1-2.5) with low-dose HFA triamcinolone [32].

The current finding of a significant improvement in the Quality of Life Questionnaire scores (overall and symptoms), in the absence of any significant change in global physiological measures, could be a reflection of improved distal airways air-trapping, as detected by the imaging studies. Prior studies of montelukast have also shown improvements in asthma quality of life, often without dramatic FEV1 changes $[33,34]$.

In conclusion, using quantitative lung imaging techniques, the present study demonstrated a reduction in regional airtrapping (most likely due to increased small airways patency), but no reduction in regional hyperreactivity to methacholine (increased air-trapping due to methacholine-induced constriction of small airways) after treatment with an oral leukotriene receptor antagonist. Further studies, including histopathological, immunohistological and patient-reported clinical end-points, in larger samples of asthmatic subjects are needed to determine the biological and clinical significance of these findings.

\section{ACKNOWLEDGEMENTS}

The authors would like to thank: J. Plocky and C. Lee as study coordinators; E. Lee and R. Ferrill as pulmonary function technicians; and S. Tam for additional help in image analysis.

\section{REFERENCES}

1 Saetta M, Di Stefano A, Rosina C, Thiene G, Fabbri LM. Quantitative structural analysis of peripheral airways and arteries in sudden fatal asthma. Am Rev Respir Dis 1991; 143: 138-143.

2 Kuwano K, Bosken CH, Pare PD, Bai TR, Wiggs BR, Hogg JC. Small airways dimensions in asthma and in chronic obstructive pulmonary disease. Am Rev Respir Dis 1993; 148: 1220-1225.

3 Carroll N, Elliot J, Morton A, James A. The structure of large and small airways in nonfatal and fatal asthma. Am Rev Respir Dis 1993; 147: 405-410.

4 Hamid Q, Song Y, Kotsimbos TC, et al. Inflammation of small airways in asthma. J Allergy Clin Immunol 1997; 100: 44-51.

5 Minshall EM, Hogg JC, Hamid QA. Cytokine mRNA expression in asthma is not restricted to the large airways. $J$ Allergy Clin Immunol 1998; 101: 386-390.

6 Kraft M, Djukanovic R, Wilson S, Holgate ST, Martin RJ. Alveolar tissue inflammation in asthma. Am J Respir Crit Care Med 1996; 154: 1505-1510.

7 Sherter CB, Connolly JJ, Schilder DP. The significance of volume-adjusting the maximal midexpiratory flow in assessing the response to a bronchodilator drug. Chest 1978; 73: 568-571.

8 McFadden ER Jr, Holmes B, Kiker R. Variability of closing volume measurements in normal man. Am Rev Respir Dis 1975; 111: 135-140.

9 in 't Veen JC, Beekman AJ, Bel EH, Sterk PJ. Recurrent exacerbations in severe asthma are associated with enhanced airway closure during stable episodes. Am J Respir Crit Care Med 2000; 161: 1902-1906.

10 McNitt-Gray MF, Goldin JG, Johnson TD, Tashkin DP, Aberle DR. Development and testing of image-processing methods for the quantitative assessment of airway hyperresponsiveness from high-resolution CT images. J Comput Assist Tomogr 1997; 21: 939-947.

11 Goldin JG, McNitt-Gray MF, Sorenson SM, et al. Airway hyperreactivity: assessment with helical thin-section CT. Radiology 1998; 208: 321-329.

12 Newman KB, Lynch DA, Newman LS, Ellegood D, Newell JD Jr. Quantitative computed tomography detects air trapping due to asthma. Chest 1994; 106: 105-109.

13 Goldin JG, Tashkin DP, Kleerup EC, et al. Comparative effects of hydrofluoroalkane and chlorofluorocarbon beclomethasone dipropionate inhalation on small airways: assessment with functional helical thin-section computed tomography. J Allergy Clin Immunol 1999; 104: S258-S267.

14 Hankinson JL, Odencrantz JR, Fedan KB. Spirometric reference values from a sample of the general U.S. population. Am J Respir Crit Care Med 1999; 159: 179-187.

15 West JB. State of the art: ventilation-perfusion relationships. Am Rev Respir Dis 1977; 116: 919-943. 
16 Buist AS, Ross BB. Closing volume as a simple, sensitive test for the detection of peripheral airway disease. Chest 1973; 63: 29S-30S.

17 Crapo RO, Morris AH, Clayton PD, Nixon CR. Lung volumes in healthy nonsmoking adults. Bull Eur Physiopathol Respir 1982; 18: 419-425.

18 Juniper EF, Buist AS, Cox FM, Ferrie PJ, King DR. Validation of a standardized version of the Asthma Quality of Life Questionnaire. Chest 1999; 115: 1265-1270.

19 Revicki DA, Leidy NK, Brennan-Diemer F, Sorensen S, Togias A. Integrating patient preferences into health outcomes assessment: the multiattribute Asthma Symptom Utility Index. Chest 1998; 114: 998-1007.

20 Juniper EF, O'Byrne PM, Guyatt GH, Ferrie PJ, King DR. Development and validation of a questionnaire to measure asthma control. Eur Respir J 1999; 14: 902-907.

21 Pifferi M, Caramella D, Ragazzo V, Pietrobelli A, Boner AL. Low-density areas on high-resolution computed tomograms in chronic pediatric asthma. J Pediatr 2002; 141: 104-108.

22 Mechiche H, Naline E, Candenas L, et al. Effects of cysteinyl leukotrienes in small human bronchus and antagonist activity of montelukast and its metabolites. Clin Exp Allergy 2003; 33: 887-894.

23 Snetkov VA, Hapgood KJ, McVicker CG, Lee TH, Ward JP. Mechanisms of leukotriene D4-induced constriction in human small bronchioles. Br J Pharmacol 2001; 133: 243-252.

24 Wohlsen A, Martin C, Vollmer E, et al. The early allergic response in small airways of human precision-cut lung slices. Eur Respir J 2003; 21: 1024-1032.

25 Bjermer L. History and future perspectives of treating asthma as a systemic and small airways disease. Respir Med 2001; 95: 703-719.

26 Tashkin DP, Goldin JG, Kleerup EC. Evaluation of small airways and the impact of inhaled steroids-size does matter. In: Wenzel SE, ed. Asthma and the Small Airways. New York, American Thoracic Society, 2000; pp. 7-15.

27 Grenier P, Mourey-Gerosa I, Benali K, et al. Abnormalities of the airways and lung parenchyma in asthmatics: CT observations in 50 patients and inter- and intraobserver variability. Eur Radiol 1996; 6: 199-206.

28 Currie GP, Lee DK, Haggart K, Bates CE, Lipworth BJ. Effects of montelukast on surrogate inflammatory markers in corticosteroid-treated patients with asthma. Am J Respir Crit Care Med 2003; 167: 1232-1238.

29 Baumgartner RA, Martinez G, Edelman JM, et al. Distribution of therapeutic response in asthma control between oral montelukast and inhaled beclomethasone. Eur Respir J 2003; 21: 123-128.

30 Israel E, Chervinsky PS, Friedman B, et al. Effects of montelukast and beclomethasone on airway function and asthma control. J Allergy Clin Immunol 2002; 110: 847-854.

31 Leff JA, Busse WW, Pearlman D, et al. Montelukast, a leukotriene-receptor antagonist, for the treatment of mild asthma and exercise-induced bronchoconstriction. $N$ Engl J Med 1998; 339: 147-152.

32 Dempsey OJ, Kennedy G, Lipworth BJ. Comparative efficacy and anti-inflammatory profile of once-daily therapy with leukotriene antagonist or low-dose inhaled corticosteroid in patients with mild persistent asthma. J Allergy Clin Immunol 2002; 109: 68-74.

33 Riccioni G, Ballone E, D'Orazio N, et al. Effectiveness of montelukast versus budesonide on quality of life and bronchial reactivity in subjects with mild-persistent asthma. Int J Immunopathol Pharmacol 2002; 15: 149-155.

34 Malmstrom K, Rodriguez-Gomez G, Guerra J, et al. Oral montelukast, inhaled beclomethasone, and placebo for chronic asthma. A randomized, controlled trial. Montelukast/Beclomethasone Study Group. Ann Intern Med 1999; 130: 487-495. 